\title{
Synthesis and Physicochemical Studies of Polyvinyl Alcohol Polymer Modified with Copper Thiosemicarbazide Complex
}

\author{
Esraa Elsayed Elmorsy 1(i), Amr Mohamed Abdelghany 2,*iD, Dalia Mokhtar Ayad 1iD, Ola Ahmed El \\ Gammal 1,* iD \\ 1 Chemistry Department, Faculty of Science, Mansoura University, Mansoura, 35516, Egypt \\ 2 Spectroscopy Department, Physics Division, National Research Centre, 33 Elbehouth St., Dokki, 12311, Giza, Egypt \\ * Correspondence: a.m_abdelghany@yahoo.com (A.M.A.); olaelgammal@yahoo.com (OAE);
}

Scopus Author ID 7003638023

Received: 20.03.2021; Revised: 25.04.2021; Accepted: 28.04.2021; Published: 7.05.2021

\begin{abstract}
Thiosemicarbazones (TSCs) represent a category of chemical compounds that attract diverse research groups' attention due to their wide and extended applications in different pharmaceutical and agrochemical applications. Complexation reactions between the ligand and $\mathrm{CuCl}_{2}$ resulted in the formation of $\left[\mathrm{Cu}_{2}\left(\mathrm{H}_{2} \mathrm{MTS}\right) \mathrm{Cl}_{2}\left(\mathrm{H}_{2} \mathrm{O}\right)_{4}\right]$. X-ray diffraction data analysis of the studied complex suggests octahedral structure, while characterization through elemental, thermal, magnetic, and spectral (UV, IR, NMR, and ESR) analyses showed the formation of the complex. Thin films of pure polyvinyl alcohol and other samples containing different mass fractions of CuTSCs were successfully prepared through the traditional solution casting technique. Studies of the synthesized thin films show a notable change of crystallinity, optical band gap, refractive index, dielectric primitivity, and other physical properties with increasing copper complex. Besides, synthesized samples show an observed activity against different pathogenic grams. Increasing copper complex content also shows a prominent change in different samples' swelling rates, suggesting that metal complex acts as a controlled cross-linker for polyvinyl alcohol (PVA) polymer.
\end{abstract}

Keywords: Thiosemicarbazide; PVA; FTIR; UV/Vis.; XRD.

(C) 2021 by the authors. This article is an open-access article distributed under the terms and conditions of the Creative Commons Attribution (CC BY) license (https://creativecommons.org/licenses/by/4.0/).

\section{Introduction}

Thiosemicarbazones (TSCs) and their metal complexes are compounds that have been investigated extensively due to their biological activities [1-4]. Within the early 20th century, thiosemicarbazones were utilized as antituberculosis and leprosy drugs [2,3] antiviral agents and used for treatment for smallpox recently [4]. Several researchers extended the research to include their antitumor activity and tried to develop them as anticarcinogenic agents within clinical phase II on several cancer types [5-7]. Also, TSCs have been used as reagents to determine metals spectrophotometrically, device applications relative to telecommunications and optical storage. As it is well known, TSCs exist in tautomeric thione (A) and thiol (B) forms [8-10]. The existence of tautomeric forms as an equilibrium mixture in solution is essential for their versatile chelating behavior [11, 12].

Polyvinyl alcohol (PVA) is a polymer that exhibited much potential in medicinal and biomedical applications due to its beneficial properties [13]. The intrinsic hydrophilicity of 
poly(vinyl alcohol) (PVA) makes it a desirable polymer for diverse applications significantly when modified through blending or doping [14-16]. In addition, PVA possesses high water permeability, high thermal and chemical resistance and a high anti-fouling capability. PVA must be sufficiently crosslinked to overcome its high welling potential before use to ensure that pollutants in water are preserved and that compaction under pressure is minimized. It is difficult to do this while still obtaining cost-effective permeate fluxes. Many different reagents have been investigated [17]. The crosslinking agent glutaraldehyde is more efficient than formaldehyde or glycidyl acrylate, resulting in a less swollen substance than that produced from increasing crystallinity by heating [18]. For preparing of reverse osmosis membranes, toluene diisocyanate and acrolein are used to produce comparable effects but at a much higher applied strain. Crosslinking with maleic anhydride/vinyl methyl ether copolymers produces similar results at a higher strain. Thus, high swelling of PVA could be overcome by crosslinking reactions by consuming some of the $\mathrm{OH}$ groups responsible for its hydrophilicity. Pervaporation is used to separate organic compounds from one another or water, and similar membranes are used to selectively move the vapor of one ingredient across the membrane based on polarity variations $[19,20]$. PVA membranes will be ideal for dehydration procedures in this case.

The present work aims to investigate the physicochemical characteristics of polyvinyl alcohol polymer modified with different mass fractions of copper thiosemicarbazide complex (PVA/CuTSCs) and the possibility to be a candidate in different optical applications adopting nonlinear optical characteristics.

\section{Materials and Methods}

\subsection{Material used.}

All chemicals were of high grade. Hydrazine hydrate monohydrate, diethyl malonate and p-methoxyphenyl isothiocyanate, ethanol and diethyl ether were from Aldrich-Sigma company.PVA, the main material used, is fine white powder odorless PVA [Mw=6000 $\mathrm{gmol}^{-}$ ${ }^{1}$, Laboratory Rasayan], and thiosemicarbazide ligand.

\subsection{Synthesisof 2,2'-malonylbis(N-(4-methoxyphenyl)hydrazine-1-carbothioamide)} (H6PMTS).

The present Tsc, $\mathrm{H}_{6} \mathrm{PMTS}$ ligand was prepared by reacting malonyl hydrazide with pmethoxy phenyl isothiocyanate in (1:2) molar ratio in hot ethanol and heating under reflux for $3 \mathrm{hr}$. The precipitate formed was filtered off, washed and dried under vacuum. The product was characterized by TLC, elemental analysis (C, H, N \& S) and spectral (IR, UV/Vis, NMR) measurements., and preparation of copper complexes with thiosemicarbazide.

$\mathrm{C}_{19} \mathrm{H}_{25} \mathrm{O}_{4} \mathrm{~N}_{6} \mathrm{~S}_{2}$ (401.405): Yield: 85\% (5.50 g) Page; m.p.:300 ${ }^{\circ} \mathrm{C}$; Elemental Anal. \% Calc; C (56.85); H(6.28); N (20.93); S(15.97); Found: C 46.20 .H 4.31; N 13.25; FTIR (cm $\left.{ }^{1}\right): 3109 v(\mathrm{~N} 1 \mathrm{H}) ; 3230 v(\mathrm{~N} 4 \mathrm{H}) ; 3198 v(\mathrm{~N} 2 \mathrm{H}) ; 1706$; $(\mathrm{C}=\mathrm{O})$ bonded; 1675(v(C=O)hydrazine; 1650 $(v(\mathrm{C}=\mathrm{O})$ benzoyl; 1558v $(\mathrm{C}=\mathrm{N})$ azo; $1322 \delta(\mathrm{C}-\mathrm{H}) ; 919 \delta(\mathrm{N}-\mathrm{H}) ; 1246 v(\mathrm{C}=\mathrm{S}) ; 824 \delta(\mathrm{C}=\mathrm{S})$; $1613 v(\mathrm{C}=\mathrm{C})$ phenyl; $1045 v(\mathrm{~N}-\mathrm{N}) ; 3062(\mathrm{CH})$ aromatic. 


\subsection{Synthesis of the copper complex.}

$25 \mathrm{ml}$ hot ethanolic solution of $1 \mathrm{mmol} \mathrm{CuCl}_{2} .4 \mathrm{H}_{2} \mathrm{O}$ salt were added to hot ethanolic solution $(0.46211 \mathrm{mmol})$ of $\mathrm{H}_{6} \mathrm{PMTS}$, heating the mixture under reflux for $2 \mathrm{~h}$ till brown precipitate wasformed, filtered off, washed with ethanol followed by diethyl ether and dried under anhydrous $\mathrm{CaCl}_{2}$. The complex obtained is found to be nonelectrolyte $\left(\Omega=11 \mathrm{ohm}-1 \mathrm{~cm}^{2}\right.$ ) stable in air and soluble in both dimethylformamide (DMF) and dimethyl sulfoxide (DMSO) [8]. [Cu $\left.2\left(\mathrm{H}_{4} \mathrm{PMTS}\right)(\mathrm{Cl})_{2}\left(\mathrm{H}_{2} \mathrm{O}\right)_{2}\right]$ : Yield: (88\%). Color: Pale brown. m.p.: $296.5{ }^{0} \mathrm{C}$. Anal. Found (Calcd for $\mathrm{C}_{20} \mathrm{H} 30 \mathrm{Cl}_{2} \mathrm{Cu}_{2} \mathrm{~N} 6 \mathrm{O} 8 \mathrm{~S} 2$, 744.61): C, 39.17 (32.26); H, 3.51 (4.06); N, 11.98 (11.28);S, (8.61) Cu, 21.09 (17.06); Cl, (9.5). Main IR (KBr) : $1675 v(\mathrm{C}=\mathrm{O})$ hy; 1601 $v(\mathrm{C}=\mathrm{N}) \mathrm{azo} ; 1300 \delta(\mathrm{C}-\mathrm{H}) ; 920 \delta(\mathrm{N}-\mathrm{H}) ; 1268 v(\mathrm{C}=\mathrm{S}) ; 823 \delta(\mathrm{C}=\mathrm{S}) ; 1601 v(\mathrm{C}=\mathrm{C})$ phenyl; 1029 $v(\mathrm{~N}-\mathrm{N}) ; 3060(\mathrm{CH})$ aromatic.

\subsection{Films preparation.}

Precalculated amount of Polyvinyl alcohol (PVA) was dissolved separately in a suitable amount of DMSO at $50{ }^{\circ} \mathrm{C}$ vigorously stirred. Weight per volume of the studied H6PMTS was also dissolved in DMSO. The metal complex was added to the viscous dissolved polymer and kept at the same condition for about $3 \mathrm{~h}$ with a required concentration listed in Table 1 to ensure complete interaction between polymer and metal complex.

Table 1. Nominal composition and nomination of studied samples.

\begin{tabular}{l|l|l|l|l|l} 
Sample & S0 & S1 & S2 & S3 & S4 \\
\hline PVA & 100 & 99.975 & 99.950 & 99.925 & 99.900 \\
\hline H6PMTS & 0.0 & 0.0250 & 0.050 & 0.075 & 0.100
\end{tabular}

\subsection{Swelling rate test.}

The experiment performed using a thin polymer film of the nearly constant area and thickness placed in a known mass permeable bag suspended over a beaker filled with the test liquid of known $\mathrm{pH}$. The weights of polymer thin film were measured before $\left(W_{l}\right)$ and after swelling $\left(W_{2}\right)$ for a fixed time interval (usually 30min), and the swelling rate was calculated using the formula [21]:

$$
S R \%=\frac{W 2-W 1}{W 1} \times 100
$$

\subsection{Characterization techniques.}

XRD pattern (Figure 1) obtained within Bragg angles (2Ө) extended between (5-80 ) recorded via PANalytical X Pert machine at $30 \mathrm{kV}$ adopting $\mathrm{CuK} \alpha$ lines at wavelength 1.5418 $\AA$. FT-IR absorption spectral data collected through 32 scans within the range extended from $4000-400 \mathrm{~cm}^{-1}$ with a spatial resolution $2 \mathrm{~cm}^{-1}$ via Nicolet iS10, to identify the fingerprint vibrations correlated with specific functional groups. UV/Vis. electronic absorption spectra were determined in the wavelength region 200-1000 nm using a spectrophotometer (Jascov 570). ${ }^{1} \mathrm{H},{ }^{13} \mathrm{C}$ - NMR spectra of the prepared Tsc and the 13C NMR spectra of the ligands were recorded in DMSO-d6 on ECA spectrophotometer (500 MHZ). The percentages of C, H, and $\mathrm{N}$ content in the ligands and their metal complexes were evaluated. Thermogravimetric analysis (TGA D TGA) for the compounds was done at a temperature range $\left(\mathrm{r}-\mathrm{t}-800^{\circ} \mathrm{C}\right)$ by $(\mathrm{TGA}-50 \mathrm{H}$ Shimadzu thermogravimetric). ESR spectrum of powdered $\mathrm{Cu}^{+2}$ complex were recorded on an 
X-band $(9.78 \mathrm{GHz})$ by (Bruker EMX spectrometer) with $100 \mathrm{kHz}$ modulation frequency at room temperature.

\section{Results and Discussion}

\subsection{Complex justification.}

FTIR spectral data of the studied H6PMTS with chemical structure shown in Scheme 1 revealed three basic vibrational groups with bands originally located at 3230, 3109, and 3198 $\mathrm{cm}^{-1}$ with a shoulder at $3246 \mathrm{~cm}^{-1}$ usually assigned for $v(\mathrm{~N} 4 \mathrm{H}), v(\mathrm{~N} 1 \mathrm{H}), v(\mathrm{~N} 2 \mathrm{H})$ respectively. Besides, sharp, intense bands located at about 1706, 1675, and $1604 \mathrm{~cm}^{-1}$ can be correlated with $v(\mathrm{C}=\mathrm{O})$ bonded, $v(\mathrm{C}=\mathrm{O})$, and $v(\mathrm{C}=\mathrm{C}) \mathrm{Ph}$ vibrations. At the same time, hydrogen bonding between $\mathrm{N} 2 \mathrm{H}$ and carbonyl oxygen is usually observed at $1885 \mathrm{~cm}^{-1}$. Also, the band recognized at 1355 is attributed to $v(\mathrm{OCH} 3)$ vibrational mode. Furthermore, four new bands detected at $1558,1465,1246$, and $823 \mathrm{~cm}^{-1}$ were consigned to the formation of thioamide I, II, III, and $v(\mathrm{C}=\mathrm{S})$ vibrations, respectively. The absence of bands due to $v(\mathrm{OH})$ and $v(\mathrm{SH})$ vibrations suggested that the ligand exists in keto-thioketo form [7].
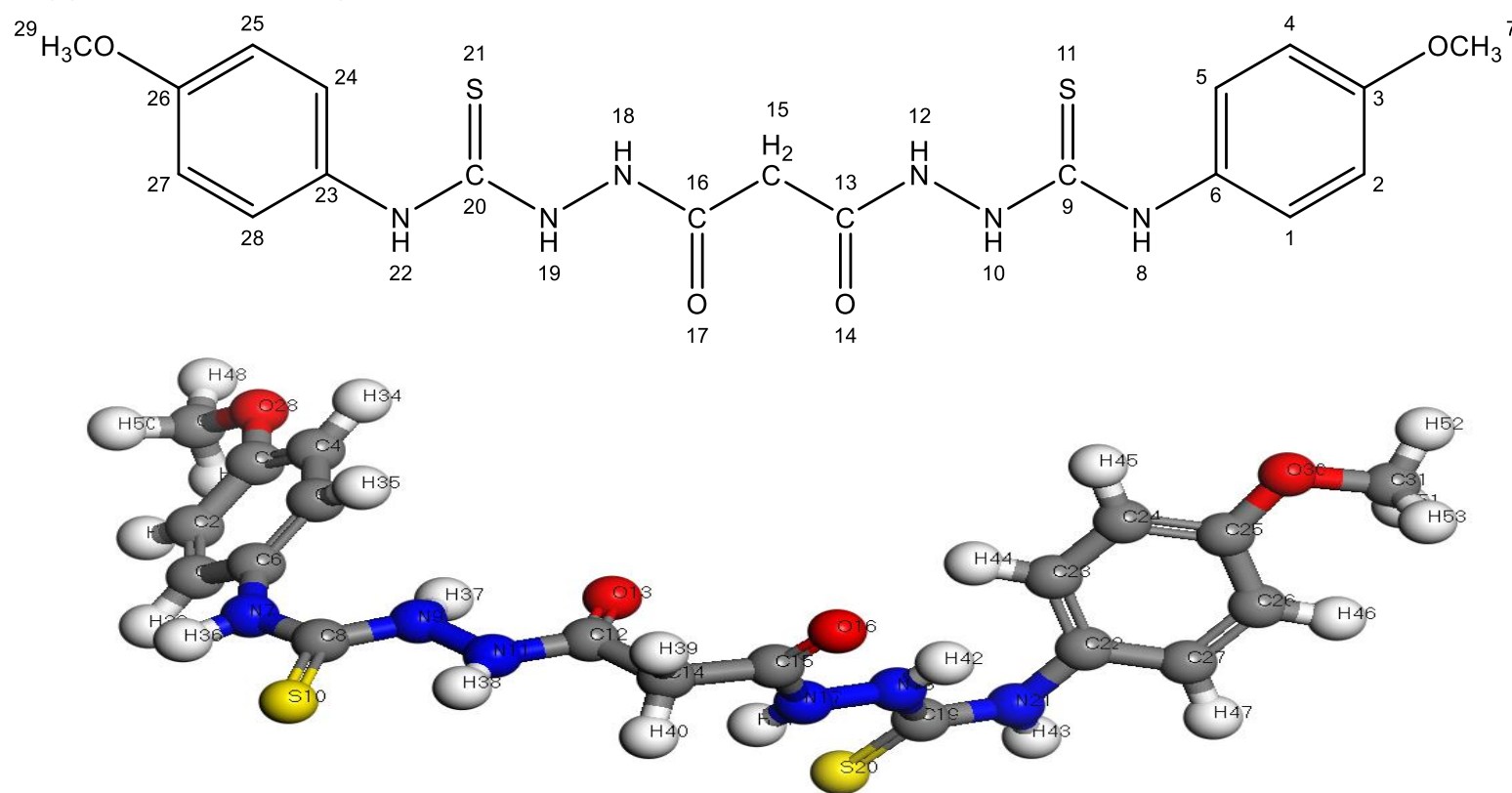

Scheme 1. 2D and 3D chemical structure of 2,2'-malonylbis(N-(4-methoxyphenyl)hydrazine-1-carbothioamide) (H6PMTS).

On comparing the spectrum of the bimetallic copper complex (Scheme 2) with that of the ligand (Figure 1), it is clear that H6PMTS binds to the metal as bi-negative ONS tridentate towards each copper atom. The symmetrical thiosemicarbazide coordinates two copper atoms, one in the enol thione form on one side and the other in keto-thiol form. The following remarks confirm this mode of chelation:-

- The disappearance of the band due to $v(C=O)$ and the $v(C=S)$ modes suffered weakness upon complexation, suggesting that the two carbonyl groups undergo enolization followed by deprotonation and thus sharing in coordination in enol form.

- The band assigned to $v\left(\mathrm{~N}^{1} \mathrm{H}\right)$ disappeared, while that due to $v\left(\mathrm{~N}^{2} \mathrm{H}\right)$ is weakened, which is an indication of participation of $\left(\mathrm{N}^{2} \mathrm{H}\right)$ group in coordination to metal ions a fivemembered chelate ring.

- The new bands observed at 1563 and $1170 \mathrm{~cm}^{-1}$ assignable to $v\left(\mathrm{C}=\mathrm{N}^{*}\right)$ and $v(\mathrm{C}-\mathrm{O})$ modes formed upon enolization of $\mathrm{C}=\mathrm{O}$ group on both sides of the ligand moiety. 
- The appearance of new bands at 583 and $515 \mathrm{~cm}^{-1}$ may be due to $v(\mathrm{M}-\mathrm{O})$ and $v(\mathrm{M}-\mathrm{N})$ vibrations support the proposed mode of chelation.

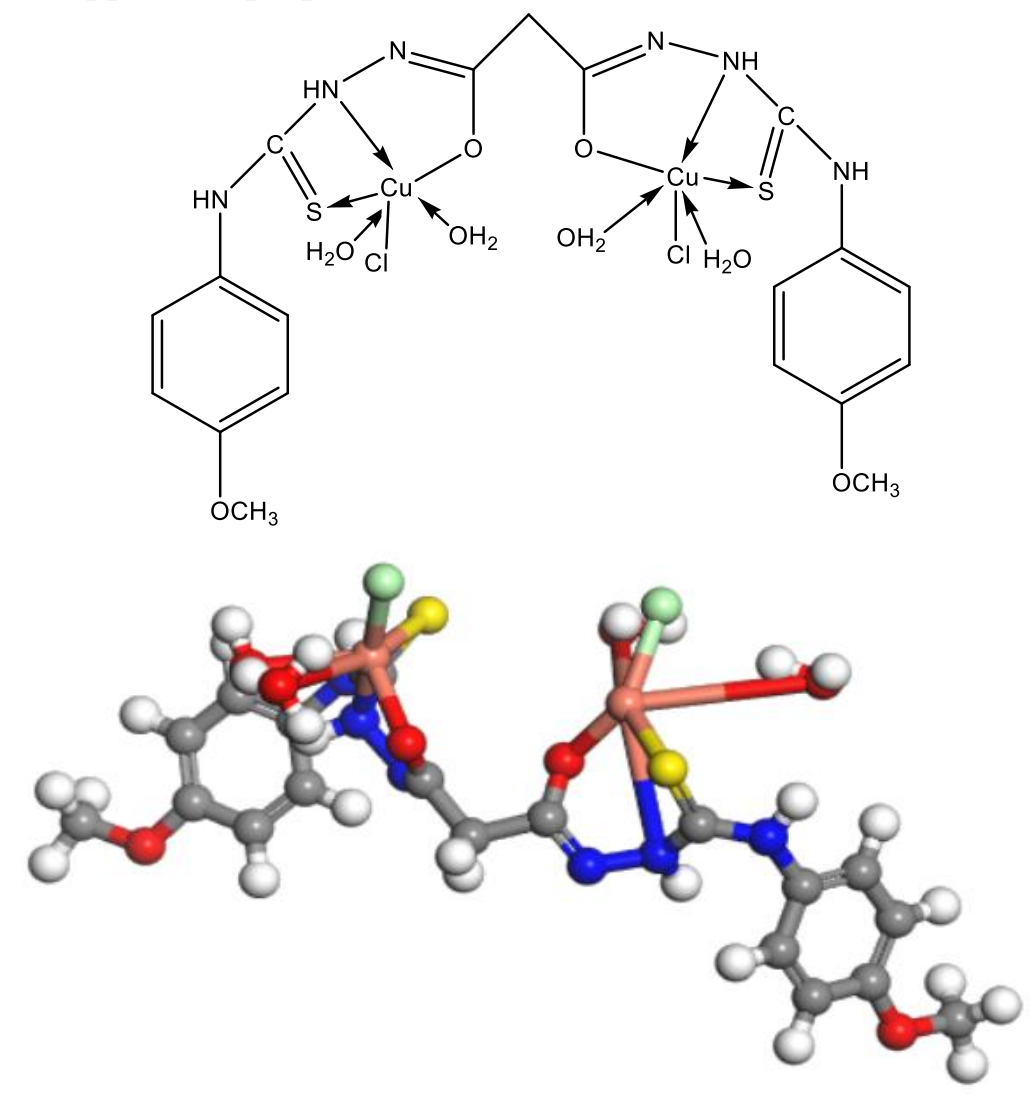

Scheme 2. 2D and 3D chemical structure of the synthesized copper complex.

The ${ }^{1}$ HNMR spectrum of the ligand, in DMSO-d6, exhibits three singlet signals at 10.27, 9.70, and $9.65 \mathrm{ppm}$ corresponding to the protons of $\mathrm{N}^{4} \mathrm{H}, \mathrm{N}^{2} \mathrm{H}$, and $\mathrm{N}^{1} \mathrm{H}$. Upon the addition of $\mathrm{D}_{2} \mathrm{O}$, the obtained spectrum indicate that these three signals were disappeared. The multiplet in the region 6.75-8Thus, the appearance and disappearance of these signals, confirms the ligand's existence in keto form.

On comparing the bimetallic copper complex spectrum with that of the ligand, it is clear that H6PMTS binds to the metal as ONS tridentate towards each copper atom. An insight to the spectrum revealed that bands due to $v(\mathrm{C}=\mathrm{O})$ and $v(\mathrm{C}=\mathrm{S})$ modes suffered weakness upon complexation, suggesting that one of the two carbonyl groups undergoes enolization followed by deprotonation and shares in coordination to one copper ion from one side while the other coordinates in keto form to the second copper atom. This model is confirmed by the disappearance of the band attributed to $v(\mathrm{~N} 1 \mathrm{H})$.

UV/Vis. electronic spectrum of thiosemicarbazide, H6PMTS, in DMSO, showed two major absorption bands located at 34250 and $32895 \mathrm{~cm}^{-1}$ previously attributed for the transition $\pi \rightarrow \pi^{*}$ of phenyl rings and both of carbonyl and thiocarbonyl groups and with a shoulder at about $25640 \mathrm{~cm}^{-1}$ correlated with the $\mathrm{n} \rightarrow \pi^{*}$ transition of thiocarbonyl, carbonyl groups. The spectrum of $\left[\mathrm{Cu}_{2}(\mathrm{H} 6 \mathrm{PMTS}) \mathrm{Cl}_{2}\left(\mathrm{H}_{2} \mathrm{O}\right)_{2}\right]$ complex showed broad bands at 13160 and $12315 \mathrm{~cm}^{-}$ ${ }^{1}$, respectively, attributed to $2 \mathrm{E}_{\mathrm{g}} \rightarrow 2 \mathrm{~T}_{2 \mathrm{~g}}$ transition of distorted octahedral geometry. 


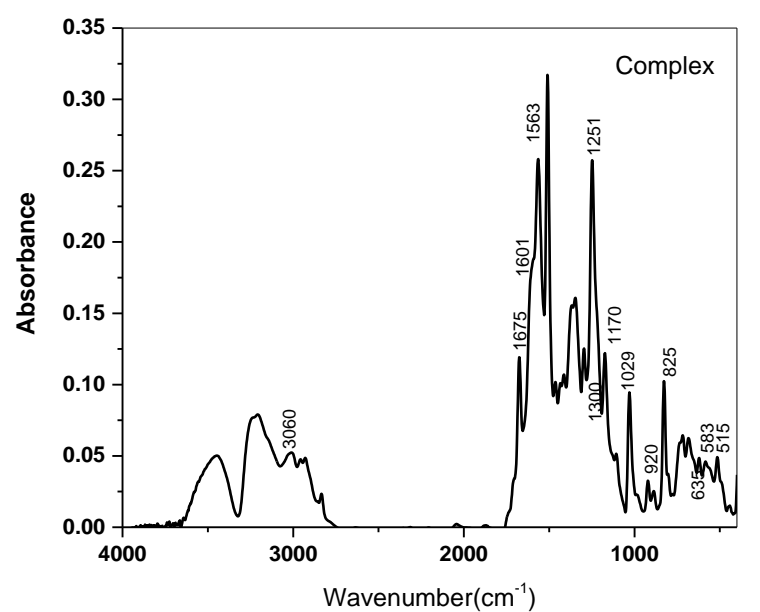

(a) FTIR

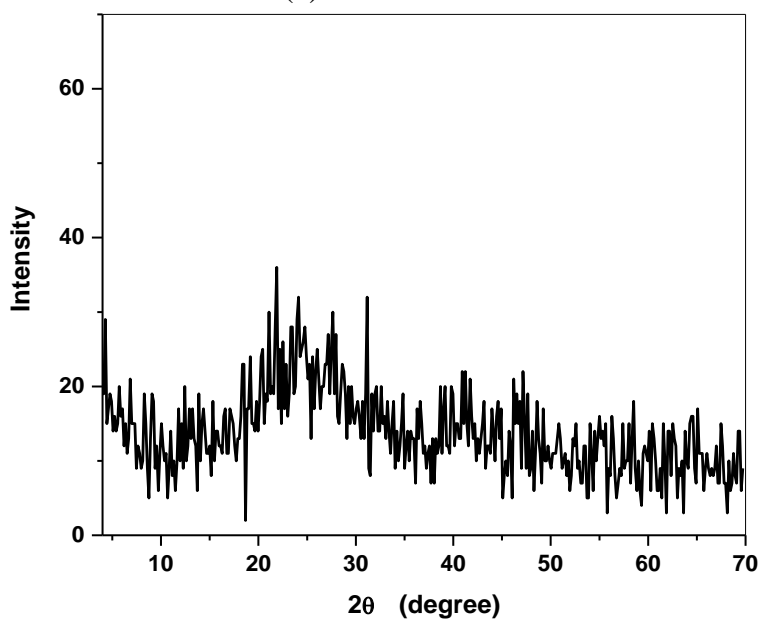

(c) XRD

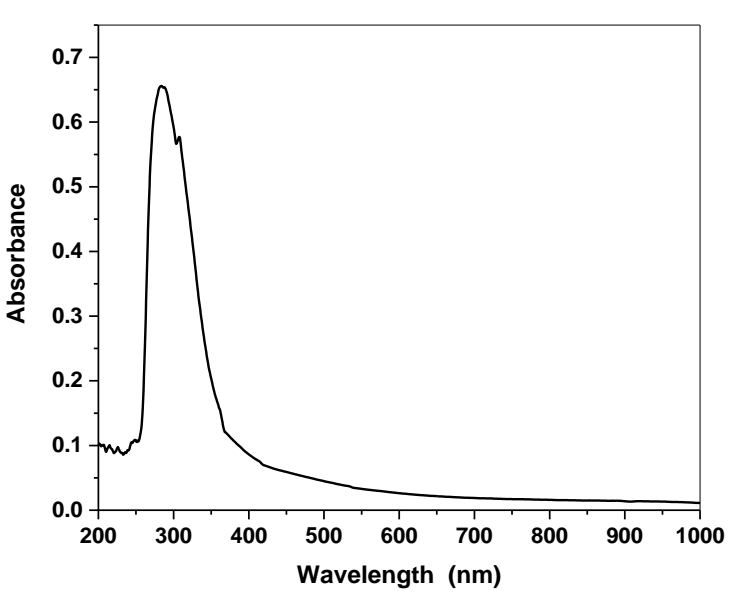

(b) UV/Vis

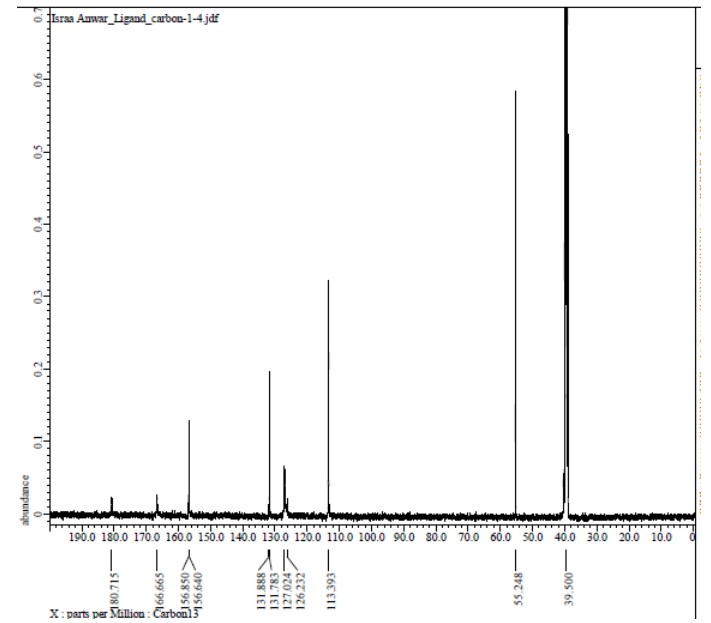

(d) C13-NMR

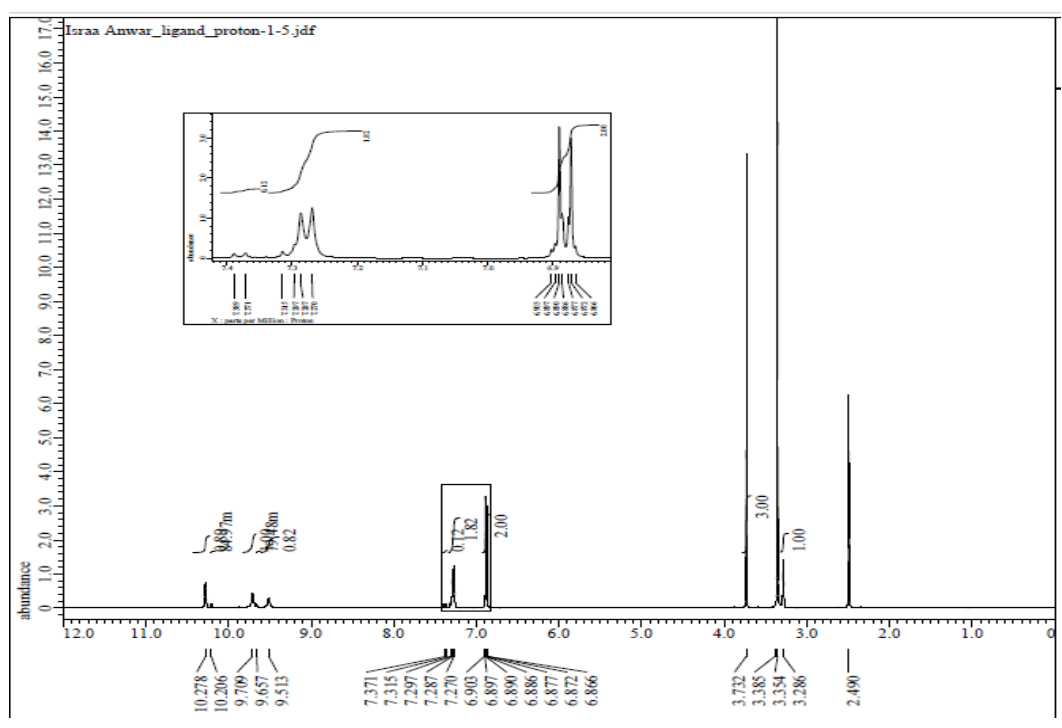

(e) Proton NMR

Figureb 1. (a) FTIR; (b) UV/Vis. Spectra; (c) XRD pattern for the complex; (d) $\mathrm{C}^{13}$; (e) ${ }^{1} \mathrm{HNMR}$ spectra for the ligand. 


\subsection{Membrane characterization.}

\subsubsection{X-ray diffraction.}

Figure 2 shows the x-ray diffraction pattern of the studied samples. Sample S0 represents the pristine polyvinyl alcohol (PVA) matrix which shows a broad medium-intensity band originally centered at about $20^{\circ}$ indicating that the studied host matrix has semicrystalline nature. This can be explained by doping the pristine polymer with the synthesized metal complex may result in some interactions that lead to this observed change in the degree of crystallinity. Therefore, the degree of crystallinity (DC \%) calculate in terms of both areas of crystalline peaks (Ac) to the area of both crystalline and background (Ab) using the formula [22]:

$$
D_{C} \%=\frac{A_{C}}{A_{C}+A_{b}} * 100
$$

As a general, it is noticed that a further increase in dopant level caused a decrease in crystallinity, as shown in Figure 2 b.

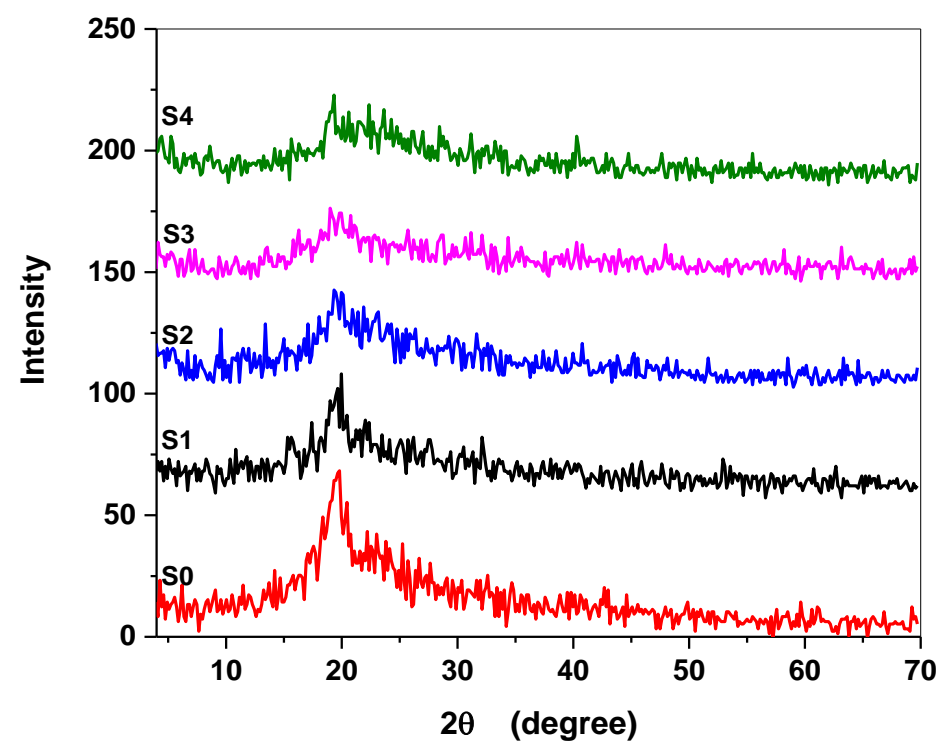

(a)

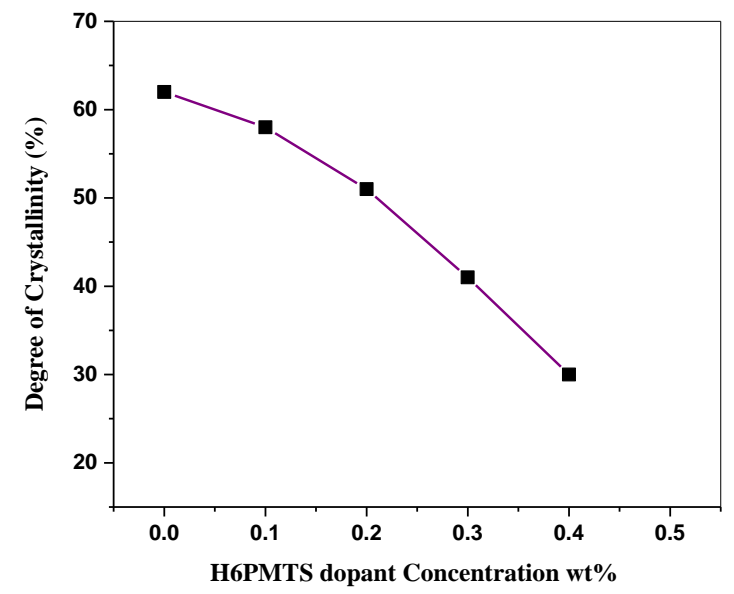

(b)

Figure 2. (a) XRD pattern of the studied polymeric samples containing different dopant concentrations; (b) variation of degree crystallinity. 


\subsubsection{FTIR spectral data.}

Figure 3 reveals the IR optical absorption spectral data of pristine polymeric matrix (PVA) S0 thin-film combined with other thin samples containing variable mass fractions up to $0.1 \%$ from the synthesized $\mathrm{H}_{6} \mathrm{PMTS}$. FTIR spectra of studied data can be distinguished through the following characteristic features:

- The broadband observed in the region $3600-3100 \mathrm{~cm}^{-1}$ is assigned to both vstretching and bending modes of the hydroxyl group of the PVA host matrix. The band centered at about 2900, $2950 \mathrm{~cm}^{-1}$ are characteristic for asymmetric and symmetric stretching vibrations of aliphatic $\mathrm{CH}_{2}$ groups.

- The sharp, intense band originally located at $1720 \mathrm{~cm}^{-1}$ corresponds to bonded $\mathrm{C}=\mathrm{O}$ stretching vibrations and confirms the intermolecular interaction between $\mathrm{OH}$ groups of PVA and dopant material and correlated with the semicrystalline nature observed from the figure (2.b).

- A sharp band around $1430 \mathrm{~cm}^{-1}$ attributed to the presence of $\mathrm{CH}_{2}$ scissoring vibration.

- The peak centered at about $1090 \mathrm{~cm}^{-1}$ assigned to stretching (N-N) vibration.

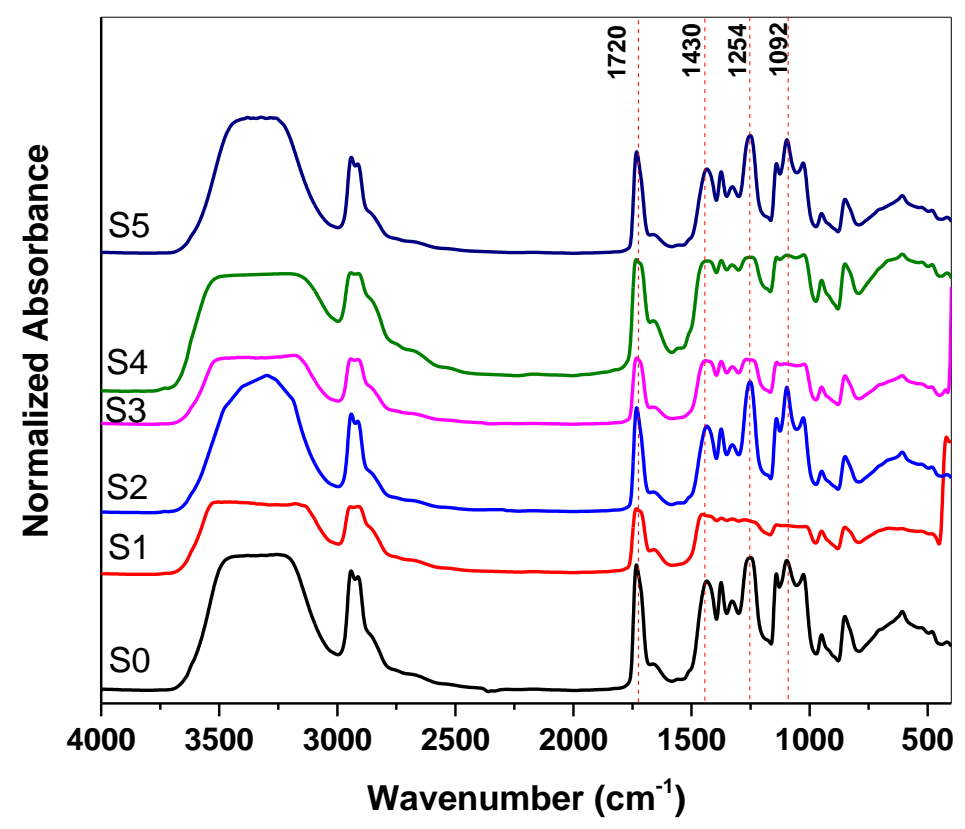

Figure 3. FTIR optical absorption spectra of prepared thin samples.

FTIR and XRD data suggested the interaction between polymeric matrix and dopant complex through the hydroxyl group of PVA can change the crystallinity level of material and makes sample suitable for different chemical and optical applications [23-25].

\subsubsection{UV/Vis. optical absorption spectra.}

Figure 4 shows UV/Vis. electronic spectra (200-1000 nm ) displayed for the studied samples, which revealed the appearance of a sharp band in all samples located at about 220 $\mathrm{nm}$, usually attributed for the $\mathrm{n} \rightarrow \pi^{*}$ transition in the host polymeric matrix and point about to the semicrystalline nature of PVA. The absorption peaks were observed at 250 and $300 \mathrm{~nm}$ on increasing metal complex content and indicating their interaction with the polymeric matrix with the absence of any sharp peaks until the end of measurements.

Figure $4 \mathrm{~b}$ and data listed in Table 2 indicate the values of the optical energy gap $\left(\mathrm{E}_{\mathrm{g}}\right)$ for both direct and indirect transitions obtained from Tauc's plot of photon energy $(h v)$ versus 
both $(\alpha h v)^{1 / 2}$ and $(\alpha h v)^{2}$ respectively for selected samples. Table 2 also contains, the refractive index and dielectric permittivity of the substance relative to that of the free space for all samples under investigation that were calculated using Dimitrov and Sakaa equation [26]:

$$
\begin{aligned}
& \frac{n^{2}-1}{n^{2}+2}=1-\left(\frac{E_{g}}{20}\right)^{1 / 2} \\
& \varepsilon=n^{2}
\end{aligned}
$$

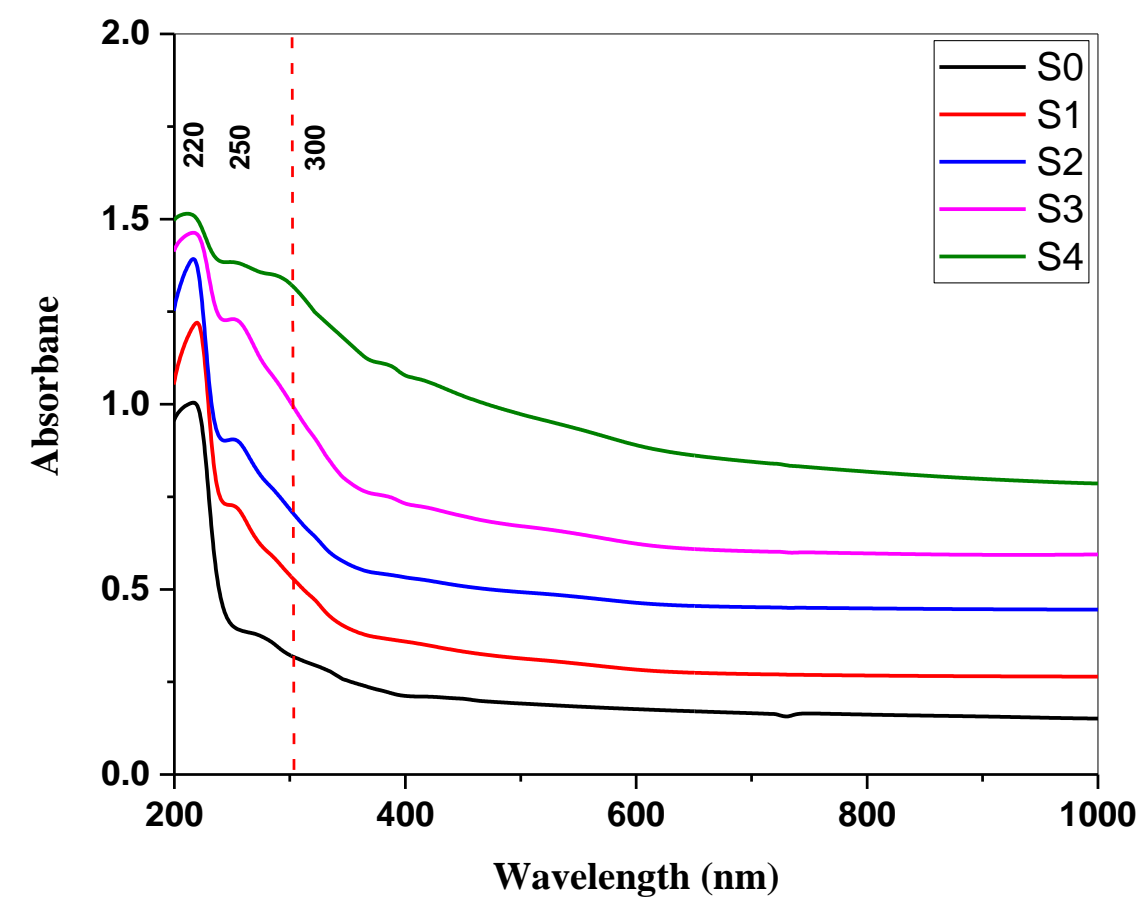

Figure 4. UV/Vis. electronic transition of the studied samples.

A notable change in energy gap was observed in both samples S3 and S4 that contain the higher dopant concentration indicating and leads to a change in both refractive index and dielectric primitivity and pointing to possible use in different medical and electrochemical applications.

Table 2. Optical energy gap and calculated physical parameters.

\begin{tabular}{l|l|l|l|l|l}
\multirow{2}{*}{ Sample } & \multirow{2}{*}{$\begin{array}{l}\text { Dopant } \\
\text { Conc.\% }\end{array}$} & \multicolumn{2}{|l|}{ Energy gap $(\mathbf{e V})$} & $\begin{array}{l}\text { Refractive } \\
\text { index }(\boldsymbol{n})\end{array}$ & $\begin{array}{l}\text { Primativity } \\
(\boldsymbol{\varepsilon})\end{array}$ \\
\hline S0 & 0 & 4.921 & 5.011 & 2.012 & 1.418 \\
\hline S1 & 0.1 & 4.769 & 4.950 & 2.035 & 1.427 \\
\hline S2 & 0.2 & 4.593 & 4.773 & 2.064 & 1.437 \\
\hline S3 & 0.3 & 4.079 & 4.356 & 2.154 & 1.468 \\
\hline S4 & 0.4 & 3.473 & 3.987 & 2.280 & 1.510
\end{tabular}

\subsection{Antimicrobial activity.}

Thiosemicarbazide complexes are extensively studied by different authors and are known to have wide-spectrum biocide behavior towards multiple viruses, bacteria, and fungi $[27,28]$. The antimicrobial activity of synthesized complex and their composite polymeric membranes containing variable concentrations of the complex were studied against gramnegative bacterium strain viz; Escherichia coli ( E. coli) and gram-positive viz Staphylococcus aureus (S. aureues). The samples of equal area and thickness were planted in agar-containing dishes (beef extract $3 \mathrm{~g}+$ agar $20 \mathrm{~g}+$ peptone $5 \mathrm{~g}$ ) cultivated at $37^{\circ} \mathrm{C}$ for $24 \mathrm{~h}$.and the diameter 
of inhibition zones was measured. The procedure was repeated three times and the average values were recorded.

Figure 5 shows the variation in the inhibition zone with the metal complex content.

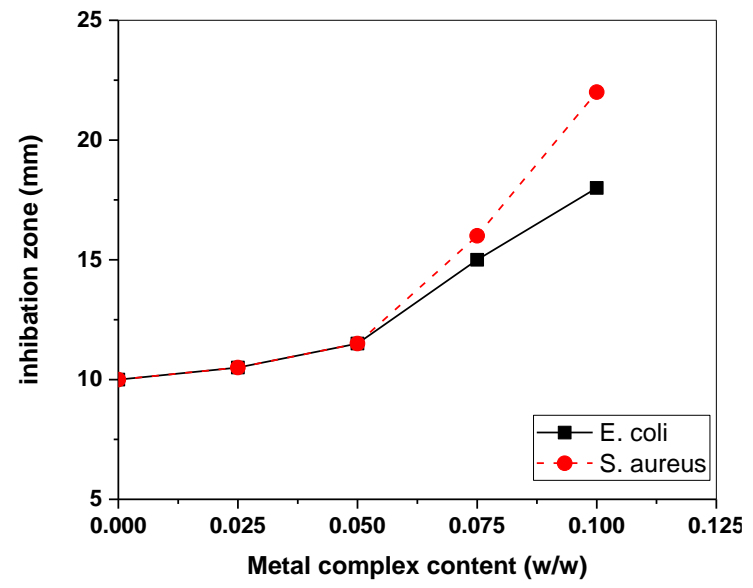

Figure 5. Variation of the inhibition zone in correlation with complex content.

It is worth predicting that the metal complex can produce biologically reactive oxygen species (ROS) that induce hydroxyl radicals $\left(\mathrm{OH}^{\circ}\right)$ combined with their high bandgap. Hole and electron pairs are also produced due to indoor light activation within both valence and conduction bands during the activation process. Hydroxyl radicals are known to facilitate permeability through the bacteria membrane and thus inhibit the growth of bacterial organisms $[7,29]$.

\subsection{Swelling rate test.}

The swelling rate test for samples containing different dopant concentrations was performed at different $\mathrm{pH}$ levels to study the material's behavior at different media for specific applications. Figure 6 reveals the effects of both $\mathrm{pH}$ and dopant concentration in the swelling rate behavior of studied samples. It was clear from Figure $6 \mathrm{a}$ that $\mathrm{pH}$ values have a minor effect in the process of swelling for the sample with a specific dopant concentration. Increasing dopant contents result in lowering of the swelling rate, which points to the interaction process between polymeric matrix and metal complex that increases complexation and interaction process resulting in a polymer crosslinking [17-18].

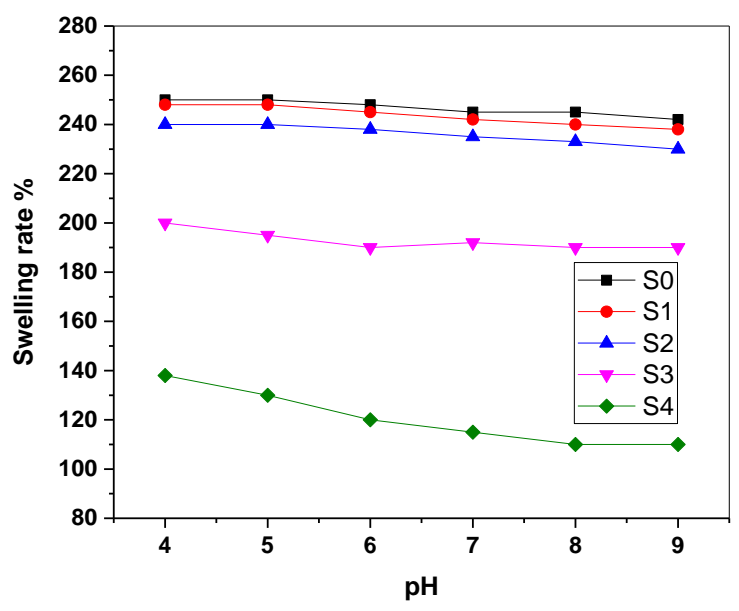

(a)

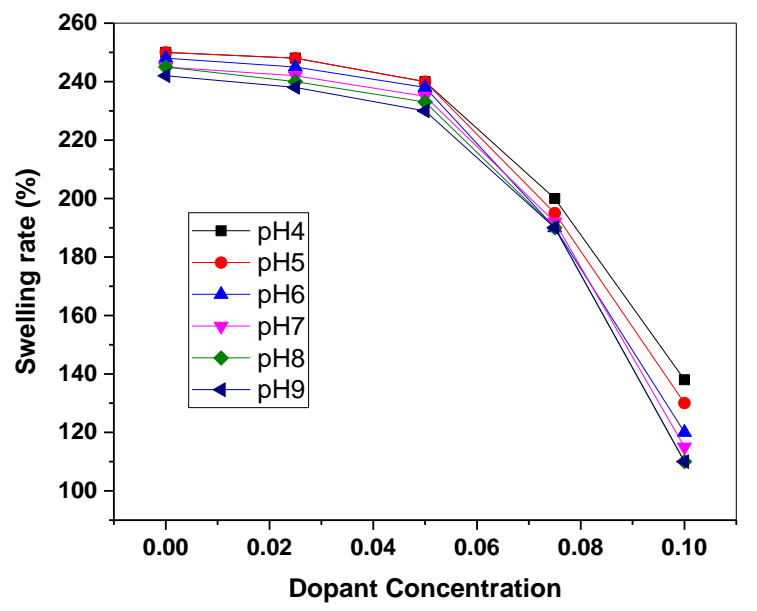

(b)

Figure 6. The effects of (a) $\mathrm{pH}$ and (b) dopant concentration on the swelling rate behavior of studied samples. 
Besides, Figure $6 \mathrm{~b}$ generally shows an exponential decrease in swelling rate with increasing complex dopant concentration and minor change in the $\mathrm{pH}$ values.

\section{Conclusions}

A new copper (II) complex of 2,2'-malonylbis(N-(4-methoxyphenyl)hydrazine-1carbothioamide) (H6PMTS) was prepared. The synthesized metal complex was fully characterized and investigated through elemental, thermal, magnetic, and spectral (XRD, UV/Vis., IR, NMR, and ESR) data. The complex afforded the molecular formula; $\left[\mathrm{Cu}_{2}\left(\mathrm{H}_{2} \mathrm{MTS} \mathrm{Cl}_{2}\left(\mathrm{H}_{2} \mathrm{O}\right)_{4}\right]\right.$ and assigned an octahedral geometry based on electronic and magnetic susceptibility measurements. Pristine and composite thin films of PVA containing variable mass fractions of CuTSCs within the doping level were successfully prepared using a simple solution casting technique. Studies of the synthesized thin films showed notable crystallinity changes, optical band gap, refractive index, dielectric primitivity, and other physical properties upon increasing copper complex content. Also, the prepared films were tested against antibacterial activity against pathogenic gram-positive and gram-negative bacteria viz E. coli and S. aureus. The data showed more antibacterial activity towards grampositive bacteria that increased with increasing CuTSCs metal complex concentration. This was correlated with the decrease in swelling rate attributed to controlling the cross-linking of the PVA by the copper (II) complex.

\section{Funding}

This research received no external funding.

\section{Acknowledgments}

This research has no acknowledgment.

\section{Conflicts of Interest}

The authors declare no conflict of interest.

\section{References}

1. Pelosi, G. Thiosemicarbazone metal complexes: from structure to activity. The Open Crystallography Journal 2010, 3, https://doi.org/10.2174/1874846501003010016.

2. Andres, S.A.; Bajaj, K.; Vishnosky, N.S.; Peterson, M.A.; Mashuta, M.S.; Buchanan, R.M.; Bates, P.J.; Grapperhaus, C.A. Synthesis, Characterization, and Biological Activity of Hybrid ThiosemicarbazoneAlkylthiocarbamate Metal Complexes. Inorg. Chem. 2020, 59, 4924-4935, https://doi.org/10.1021/acs.inorgchem.0c00182.

3. Bisceglie, F.; Bacci, C.; Vismarra, A.; Barilli, E.; Pioli, M.; Orsoni, N.; Pelosi, G. Antibacterial activity of metal complexes based on cinnamaldehyde thiosemicarbazone analogues. J. Inorg. Biochem. 2020, 203 , 110888, https://doi.org/10.1016/j.jinorgbio.2019.110888.

4. Ana, I.M.; Jorge, M.H.; Adoración, G.Q. Chemical and Biological Evaluation of Thiosemicarbazone-Bearing Heterocyclic Metal Complexes. Curr. Top. Med. Chem. 2021, 21, 59-72, https://doi.org/10.2174/1568026620666201022144004.

5. Jain, P.; Sharma, S.; Kumar, N.; Misra, N. Ni(II) and Cu(II) complexes of bidentate thiosemicarbazone ligand: Synthesis, structural, theoretical, biological studies and molecular modeling. Appl. Organomet. Chem. 2020, 34, e5736, https://doi.org/10.1002/aoc.5736. 
6. El-Gammal, O.A.; Fouda, A.E.-A.S.; Nabih, D.M. Novel Mn2+, Fe3+, Co2+, Ni2+ and Cu2+complexes of potential OS donor thiosemicarbazide: Design, structural elucidation, anticorrosion potential study and antibacterial activity. J. Mol. Struct. 2020, 1204, 127495, https://doi.org/10.1016/j.molstruc.2019.127495

7. El-Gammal, O.A.; Abdel-Latif, E.; Farag, M.G.; Abdel-Rhman, M.H. Synthesis, characterization, and anticancer activity of new binuclear complexes of 2,2'-malonylbis(N-phenylhydrazine-1-carbothioamide). Appl. Organomet. Chem. 2021, 35, e6194,. https://doi.org/10.1002/aoc.6194.

8. Mortada, W.I. Recent developments and applications of cloud point extraction: A critical review. Microchem. J. 2020, 157, 105055, https://doi.org/10.1016/j.microc.2020.105055.

9. Sahebi, R. Comment on: "Investigation on nucleation kinetics, growth, optical, mechanical, conductivity and Z-scan studies on thiosemicarbazide cadmium chloride monohydrate (TSCCCM) single crystals for nonlinear applications" [J. Mater. Sci. Mater. Electron. 30(6), 15116-15129 (2019)]. Journal of Materials Science: Materials in Electronics 2020, 31, 12041-12043, https://doi.org/10.1007/s10854-020-03819-4.

10. Aguzue, O.C.; Oviawe, A.P.; Olajide, O.O.; Afolayan, M.O.; Adedirin, O. Solvent-free Synthesis and Characterization of $\mathrm{Cu}$ (II), Co (II) and Ni (II) Complexes of 2-(3-phenylallylidene) thiosemicarbazide. Journal of Science and Mathematics Letters 2021, 9, 11-18, https://doi.org/10.37134/jsml.vol9.1.2.2021

11. Fabra, D.; Matesanz, A.I.; Herrero, J.M.; Alvarez, C.; Balsa, L.M.; Leon, I.E.; Quiroga, A.G. Two Different Thiosemicarbazone Tauto-Conformers Coordinate to Palladium (II). Stability and Biological Studies of the Final Complexes. Eur. J. Inorg. Chem. 2021, 2021, 1041-1049, https://doi.org/10.1002/ejic.202001066.

12. Şen Yüksel, B. Spectroscopic characterization (IR and NMR), structural investigation, DFT study, and Hirshfeld surface analysis of two zinc(II) 2-acetylthiophenyl-thiosemicarbazone complexes. J. Mol. Struct. 2021, 1229, 129617, https://doi.org/10.1016/j.molstruc.2020.129617.

13. Klicova, M.; Klapstova, A.; Chvojka, J.; Koprivova, B.; Jencova, V.; Horakova, J. Novel double-layered planar scaffold combining electrospun PCL fibers and PVA hydrogels with high shape integrity and water stability. Mater. Lett. 2020, 263, 127281, https://doi.org/10.1016/j.matlet.2019.127281.

14. Farea, M.O.; Abdelghany, A.M.; Meikhail, M.S.; Oraby, A.H. Effect of cesium bromide on the structural, optical, thermal and electrical properties of polyvinyl alcohol and polyethylene oxide. Journal of Materials Research and Technology 2020, 9, 1530-1538, https://doi.org/10.1016/j.jmrt.2019.11.078.

15. Ahmed, M.K.; Menazea, A.A.; Abdelghany, A.M. Blend biopolymeric nanofibrous scaffolds of cellulose acetate/ $\varepsilon$-polycaprolactone containing metallic nanoparticles prepared by laser ablation for wound disinfection applications. Int. J. Biol. Macromol. 2020, 155, 636-644, https://doi.org/10.1016/j.ijbiomac.2020.03.257.

16. Sadiq, M.; Raza, M.M.H.; Murtaza, T.; Zulfequar, M.; Ali, J. Sodium Ion-Conducting Polyvinylpyrrolidone (PVP)/Polyvinyl Alcohol (PVA) Blend Electrolyte Films. J. Electron. Mater. 2021, 50, 403-418, https://doi.org/10.1007/s11664-020-08581-1.

17. Agudelo, J.I.D.; Ramirez, M.R.; Henquin, E.R.; Rintoul, I. Modelling of swelling of PVA hydrogels considering non-ideal mixing behaviour of PVA and water. Journal of Materials Chemistry B 2019, 7, 40494054, https://doi.org/10.1039/C9TB00243J.

18. Swaroop, K.; Shrikant, L.P.; Somashekarappa, H.M. Swelling Studies of PVA/Gelatin Hydrogels Synthesized Using Gamma Irradiation Technique. Current Perspectives on Chemical Sciences 2021, 9, 125131, https://doi.org/10.9734/bpi/cpcs/v9/7640D.

19. Zeeshan, M.; Dilshad, M.R.; Islam, A.; Iqbal, S.S.; Akram, M.S.; Mehmood, F.; Gull, N.; Khan, R.U. Synergistic effect of silane cross-linker (APTEOS) on PVA/gelatin blend films for packaging applications. High Perform. Polym. 2021, https://doi.org/10.1177/0954008321994659.

20. Kaur, R.; Goyal, D.; Agnihotri, S. Chitosan/PVA silver nanocomposite for butachlor removal: Fabrication, characterization, adsorption mechanism and isotherms. Carbohydr. Polym. 2021, 262, 117906, https://doi.org/10.1016/j.carbpol.2021.117906

21. Abou El-Reash, Y.G.; Abdelghany, A.M.; Leopold, K. Solid-phase extraction of $\mathrm{Cu} 2+$ and $\mathrm{Pb} 2+$ from waters using new thermally treated chitosan/polyacrylamide thin films; adsorption kinetics and thermodynamics. Int. J. Environ. Anal. Chem. 2017, 97, 965-982, https://doi.org/10.1080/03067319.2017.1376905.

22. Wibowo, E.S.; Park, B.-D. Determination of Crystallinity of Thermosetting Urea-Formaldehyde Resins Using Deconvolution Method. Macromolecular Research 2020, 28, 615-624, https://doi.org/10.1007/s13233-020-8076-2.

23. Bedier, R.A.; Yousef, T.A.; Abu El-Reash, G.M.; El-Gammal, O.A. Synthesis, structural, optical band gap and biological studies on iron (III), nickel (II), zinc (II) and mercury (II) complexes of benzyl $\alpha$-monoxime 
$\begin{array}{lllllll}\text { pyridyl thiosemicarbazone. } \quad \text { J. } & \text { Mol. } \quad \text { Struct. } & \mathbf{2 0 1 7}, & \text { 1139, }\end{array}$ https://doi.org/10.1016/j.molstruc.2017.03.054.

24. El-Gammal, O.A.; Gaber, M.; Mandour, S.A. Novel VO (IV) complexes derived from a macrochelates: Synthesis, characterization, molecular modeling and in vivo insulin-mimic activity studies. Appl. Organomet. Chem. 2020, 34, e5699, https://doi.org/10.1002/aoc.5699

25. Atta, A.; Abdel Reheem, A.M.; Abdeltwab, E. Ion beam irradiation effects on surface morphology and optical properties of ZnO/PVA composites. Surf. Rev. Lett. 2020, 27, 1950214, https://doi.org/10.1142/S0218625X19502147.

26. Dimitrov, V.; Sakka, S. Electronic oxide polarizability and optical basicity of simple oxides. I. J. Appl. Phys. 1996, 79, 1736-1740, https://doi.org/10.1063/1.360962.

27. Abdelghany, A.M.; Behairy, A. Optical parameters, antibacterial characteristics and structure correlation of copper ions in cadmium borate glasses. Journal of Materials Research and Technology 2020, 9, 1049110497, https://doi.org/10.1016/j.jmrt.2020.07.057.

28. Ayaad, D.M.; Abdelaal, M.Y.A.; Aboelkheir, A.M.; Abdelghany, A.M. Performance Enhancement of Chitosan Filled Silver Vanadate Nano-rods. Journal of Inorganic and Organometallic Polymers and Materials 2019, 29, 901-907, https://doi.org/10.1007/s10904-018-01064-1.

29. El-Gammal, O.A. Synthesis, characterization, molecular modeling and antimicrobial activity of 2-(2(ethylcarbamothioyl)hydrazinyl)-2-oxo-N-phenylacetamide copper complexes. Spectrochimica Acta Part A: Molecular and Biomolecular Spectroscopy 2010, 75, 533-542, https://doi.org/10.1016/j.saa.2009.11.007. 